\title{
Transcutaneous carbon dioxide suppresses epithelial-mesenchymal transition in oral squamous cell carcinoma
}

\author{
EIJI IWATA ${ }^{1}$, TAKUMI HASEGAWA ${ }^{1}$, DAISUKE TAKEDA ${ }^{1}$, TAKESHI UEHA ${ }^{2,3}$, \\ TERUYA KAWAMOTO ${ }^{4}$, TOSHIHIRO AKISUE ${ }^{5}$, YOSHITADA SAKAI $^{2}$ and TAKAHIDE KOMORI ${ }^{1}$ \\ ${ }^{1}$ Department of Oral and Maxillofacial Surgery, Kobe University Graduate School of Medicine; \\ ${ }^{2}$ Division of Rehabilitation Medicine, Kobe University Graduate School of Medicine; \\ ${ }^{3}$ NeoChemir Inc.; ${ }^{4}$ Department of Orthopaedic Surgery, Kobe University Graduate School of Medicine; \\ ${ }^{5}$ Division of Rehabilitation Medicine, Kobe University Graduate School of Health Sciences, Kobe, Japan
}

Received December 2, 2015; Accepted January 5, 2016

DOI: 10.3892/ijo.2016.3380

\begin{abstract}
Oral squamous cell carcinoma (OSCC) is the most common form of oral cancers. Recent studies have shown that the malignant transformation of various carcinomas, including OSCC, is associated with epithelial-mesenchymal transition (EMT), and that expression of the EMT factors are significantly associated with tumor invasion, tumor metastasis, and survival rates in OSCC patients. Hence, there is a possibility that EMT suppression may improve the prognosis of OSCC patients. Hypoxia inducible factor- $1 \alpha(\mathrm{HIF}-1 \alpha)$ is a crucial microenvironmental factor in tumor progression, which induces the expression of EMT factors. We previously reported that transcutaneous $\mathrm{CO}_{2}$ suppresses both human OSCC tumor growth and metastasis to the regional lymph nodes by improving hypoxia in treated tissue. According to this background, we hypothesized that increased EMT with HIF-1 $\alpha$ expression may increase the progression and the metastatic potential of OSCC, and that decreased hypoxia by transcutaneous $\mathrm{CO}_{2}$ could suppress EMT. In the present study, in vitro studies showed that hypoxic conditions increased the expression of HIF-1 $\alpha$ and EMT factors in OSCC cells. In addition, in vivo studies revealed that transcutaneous $\mathrm{CO}_{2}$ increased E-cadherin expression with the decreased expression of HIF-1 $\alpha$, Snail, Slug, N-cadherin, and Vimentin in tumor treatment. These results suggest that transcutaneous $\mathrm{CO}_{2}$ could suppress EMT by improving hypoxia, resulting in the reduction of metastatic potential of OSCC. The findings indicate that transcutaneous $\mathrm{CO}_{2}$ may be able to improve the prognosis of OSCC patients through the suppression of EMT.
\end{abstract}

Correspondence to: Dr Takumi Hasegawa, Department of Oral and Maxillofacial Surgery, Kobe University Graduate School of Medicine, 7-5-1 Kusunoki-cho, Chuo-ku, Kobe 650-0017, Japan E-mail: hasetaku@med.kobe-u.ac.jp

Key words: epithelial-mesenchymal transition, hypoxia, metastatic potential, oral squamous cell carcinoma, transcutaneous $\mathrm{CO}_{2}$

\section{Introduction}

Oral squamous cell carcinoma (OSCC) is the most common form of oral cancers (1). Despite advances in the diagnosis and the treatment of OSCC, the prognosis remains poor, and metastasis to the cervical lymph nodes and the remote organs is an important issue in determining the prognosis of OSCC patients $(2,3)$. Recent studies have shown that epithelialmesenchymal transition (EMT) plays an important role in tumor invasion and metastasis (4-8). In addition, many studies have shown that expression of the EMT factors are significantly associated with tumor invasion, tumor metastasis, and survival in patients with SCC, including patients with OSCC (9-19). These findings strongly indicate that EMT suppression may improve the prognosis of patients with OSCC.

Hypoxic microenvironment is a characteristic feature of solid tumors (20). Hypoxia inducible factor- $1 \alpha$ (HIF-1 $\alpha$ ), an oxygen-dependent $\alpha$ subunit of HIF which activates the transcription of metastatic genes, is strongly induced under hypoxic conditions (21). Increased expression of HIF-1 $\alpha$ induces tumor invasion and metastasis, and is associated with the activation of EMT factors (22-26). We previously demonstrated that transcutaneous $\mathrm{CO}_{2}$ suppresses the growth of primary human OSCC and metastasis to the regional lymph nodes by both improving hypoxia and increasing mitochondrial apoptosis in treated tissue (27).

According to the above background, we hypothesized that improving hypoxia by transcutaneous $\mathrm{CO}_{2}$ could suppress EMT. In the present study, we investigated whether oxygen conditions affect the expression levels of HIF-1 $\alpha$ and EMT factors in OSCC in vitro and whether transcutaneous $\mathrm{CO}_{2}$ affects these factors in OSCC in vivo.

\section{Materials and methods}

Cell culture. An oral cancer cell line, HSC-3 was used in this study (Health Science Research Resources Bank, Osaka, Japan). HSC-3 cells were established from a metastatic deposit of poorly differentiated OSCC of the tongue in a mid-internal 
jugular lymph node from a 64-year-old man (28). HSC-3 cells in Eagle's minimum essential medium (Sigma-Aldrich, St. Louis, MO, USA) supplemented with $10 \%$ fetal bovine serum (Sigma-Aldrich) and $1000 \mathrm{U} / \mathrm{ml}$ penicillin/streptomycin solution (Sigma-Aldrich) were routinely cultured in an incubator in $5 \% \mathrm{CO}_{2}$ at $37^{\circ} \mathrm{C}$. Trypsin $(0.25 \%)$ and ethylenediaminetetraacetic acid (0.02\%) (Sigma-Aldrich) solution were used to isolate cells for subculture, as previously described $(27,29)$.

Cell experiments. To investigate the effect of changing oxygen conditions on OSCC cells in vitro, a total of $1.5 \times 10^{5} \mathrm{HSC}-3$ cells per well was seeded into a 6-well plate and cultured for $24 \mathrm{~h}$. Then, HSC-3 cells were incubated for $96 \mathrm{~h}$ in two different conditions: normoxic group $\left(20 \% \mathrm{O}_{2}, 5 \% \mathrm{CO}_{2}, 75 \% \mathrm{~N}_{2}\right)$ or hypoxic group $\left(1 \% \mathrm{O}_{2}, 5 \% \mathrm{CO}_{2}, 94 \% \mathrm{~N}_{2}\right)$. After the incubation, the mRNA expression of Snail, Slug, E-cadherin, N-cadherin and Vimentin in the cells were evaluated using quantitative real-time PCR, and the expression of HIF-1 $\alpha$ in the cells was evaluated using immunoblot analysis.

Animal models. Male athymic BALB/c nude mice, aged 7-weeks, were obtained from CLEA Japan (Tokyo, Japan). The animals were maintained under pathogen-free conditions, in accordance with institutional guidelines. All animal experiments were performed in accordance with the Guidelines for Animal Experimentation at Kobe University Animal Experimentation Regulations (permission number: P120602) and were approved by the Institutional Animal Care and Use Committee.

HSC-3 cells were implanted into the back of 24 mice at doses of $2.0 \times 10^{6}$ cells in $500 \mu 1$ phosphate buffered saline (PBS), as previously described $(27,29)$. Mice were randomly divided into two treatment groups: a $\mathrm{CO}_{2}$-treated group $(\mathrm{n}=12)$ and a control group $(\mathrm{n}=12)$.

Transcutaneous $\mathrm{CO}_{2}$ treatment. Transcutaneous $\mathrm{CO}_{2}$ treatment was performed as previously described $(27,29)$. Briefly, the area of skin around the implanted tumor was covered with $\mathrm{CO}_{2}$ hydrogel. This area was then sealed with a polyethylene bag, and $100 \% \mathrm{CO}_{2}$ gas was administered into the bag (Fig. 1). Each treatment was performed for $20 \mathrm{~min}$. Control animals were treated similarly, replacing the $\mathrm{CO}_{2}$ with room air.

Treatment commenced one week after HSC-3 cell implantation and was performed twice a week for three weeks. After $24 \mathrm{~h}$ of final treatment, treated tumors were removed, and total RNA and cell lysate were extracted from half of the tumor, immediately. The other half of the tumor was formalin-fixed and paraffin-embedded for staining. Serial $10-\mu \mathrm{m}$ thick transverse sections were prepared from each block.

Quantitative real-time PCR. The mRNA expression levels of $\beta$-actin, Snail, Slug, E-cadherin, $N$-cadherin and Vimentin were analyzed using quantitative real-time PCR. Total RNA was extracted from the cells and treated tumors by selective binding to a silica-gel-based membrane using an RNeasy Mini Kit, following the manufacturer's instructions (Qiagen, Valencia, CA, USA). The cDNA was synthesized (300 ng total RNA) using the High Capacity cDNA Transcription kit (Applied Biosystems, Foster City, CA, USA).

Quantification of mRNA transcription was performed using a StepOne Real-Time PCR System (Applied Biosystems).

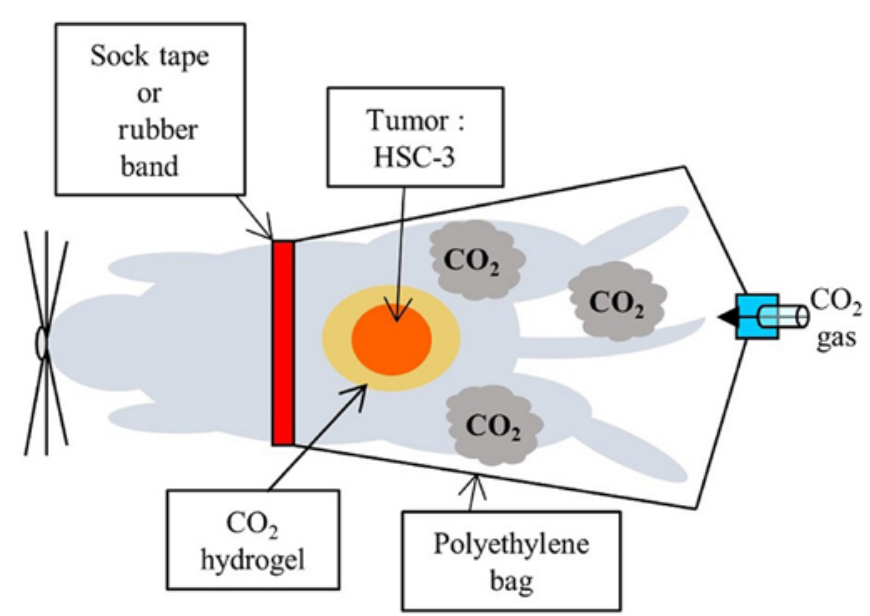

Figure 1. Transcutaneous $\mathrm{CO}_{2}$ application in an animal model of human OSCC. The area of skin around the implanted tumor was covered with $\mathrm{CO}_{2}$ hydrogel and sealed with a polyethylene bag through which $100 \% \mathrm{CO}_{2}$ gas was administered.

Real-Time PCR was performed in a $20 \mu$ l reaction mixture using SYBR Green Master Mix reagent (Applied Biosystems). PCR conditions were as follows: 1 cycle at $95^{\circ} \mathrm{C}$ for $10 \mathrm{~min}$ followed by 40 cycles at $95^{\circ} \mathrm{C}$ for $15 \mathrm{sec}$ and $60^{\circ} \mathrm{C}$ for $1 \mathrm{~min}$. The expression of each target gene was normalized to $\beta$-actin and relative expression to the control group was calculated (the $\Delta \Delta \mathrm{CT}$ method; Applied Biosystems). All primers were obtained from Invitrogen (Carlsbad, CA, USA). Primer sequences were as follows: $\beta$-actin, forward (5'-GAT GAG ATT GGC ATG GCT TT-3') and reverse (5'-CAC CTT CAC CGT TCC AGGT TT-3'); Snail, forward (5'-TGC AGG ACT CTA ATC CAA AGT TTA CC-3') and reverse (5'-GAG GGA TGG CTG CCA GC-3'); Slug, forward (5'-GTG TGG ACT ACC GCT GC-3') and reverse (5'-TCC GGA AAG AGG AGA GAG G-3'); E-cadherin, forward (5'-ACA GCA CGT ACA CAG ACCC TA-3') and reverse (5'-GCA GAA GTG TCC CTG TCC CAG-3'); $N$-cadherin, forward (5'-TTG GAT CAA TGT CAT AAT CAA GTG CTG TA -3') and reverse (5'-CTC CTA TGA GTG GAA CAG GAA CG -3'); Vimentin, forward (5'-AGC CGA AAA CAC CCT GCA AT-3') and reverse (5'-CGT TCA AGG GTC AAG ACG TGC-3').

Immunoblot analysis. Cell lysates were prepared from the cells and treated tumors using a whole cell lysis buffer supplemented with Halt protease and phosphatase inhibitor cocktail (Mammalian Protein Extraction Reagent; Thermo Scientific, Rockford, IL, USA). Protein samples were processed using standard western immunoblot procedures. Membranes were incubated overnight at $4^{\circ} \mathrm{C}$ with primary antibodies in Can Get Signal ${ }^{\circledR}$ Immunoreaction Enhancer Solution 1 (Toyobo, Osaka, Japan): anti-human-HIF-1 $\alpha$ antibody (1:1000) (Cell Signaling Technology, Danvers, MA, USA), anti-human Snail antibody (1:1000) (Cell Signaling Technology), antihuman Slug antibody (1:1000) (Cell Signaling Technology), anti-human E-cadherin antibody (1:1000) (Cell Signaling Technology), anti-human $\mathrm{N}$-cadherin antibody (1:1000) (Cell Signaling Technology), anti-human Vimentin antibody (1:1000) (Cell Signaling Technology) and anti-human $\alpha$-tubulin antibody (1:2000) (Sigma-Aldrich). After washing, 


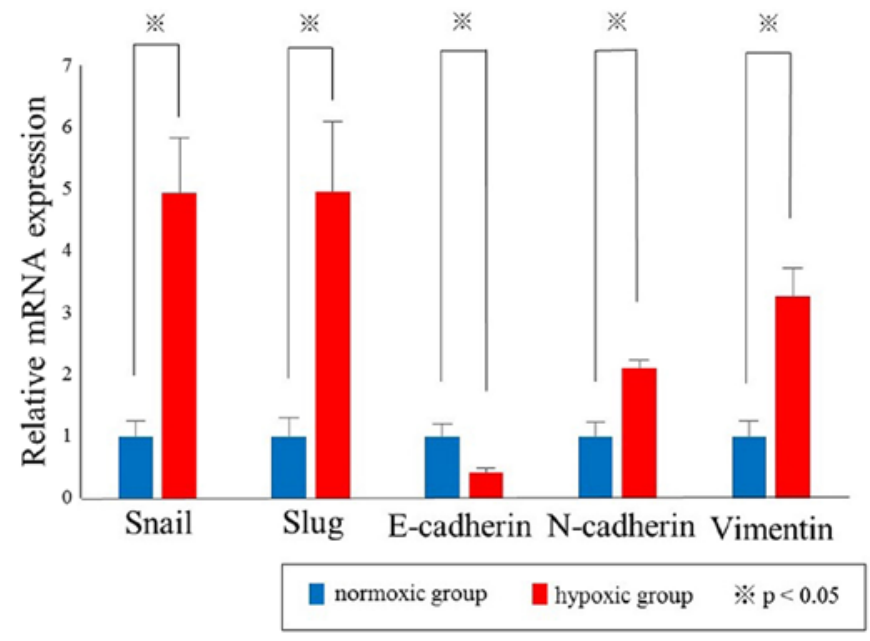

Figure 2. The mRNA expression of Snail, Slug, E-cadherin, $N$-cadherin and Vimentin were evaluated using quantitative real-time PCR $\left({ }^{*} \mathrm{p}<0.05\right)$ in vitro.

the membranes were incubated with the appropriate secondary antibody conjugated to horseradish peroxidase (GE Healthcare Bio-Sciences, Piscataway, NJ, USA) in Can Get Signal Immunoreaction Enhancer Solution 2 (Toyobo), and exposed using ECL Prime Plus Western Blotting Detection System Reagent (GE Healthcare Bio-Sciences). The signals were detected using a Chemilumino analyzer LAS-3000 mini (Fujifilm, Tokyo, Japan).

Immunohistochemical analysis. The formalin-fixed and paraffin-embedded tumor sections were pretreated with citrate buffer for $40 \mathrm{~min}$ at $95^{\circ} \mathrm{C}$, quenched with $0.05 \% \mathrm{H}_{2} \mathrm{O}_{2}$, and incubated overnight at $4^{\circ} \mathrm{C}$ with the following primary antibodies in Can Get Signal Immunostain Solution A (Toyobo): rabbit anti-human Snail antibody (1:1000) (Cell Signaling Technology), anti-human Slug antibody (1:1000) (Cell Signaling Technology), anti-human E-cadherin antibody (1:1000) (Cell Signaling Technology), anti-human N-cadherin antibody (1:1000) (Cell Signaling Technology), and anti-human Vimentin antibody (1:1000) (Cell Signaling Technology). Following the treatment, the sections were incubated with horseradish peroxidase (HRP)-conjugated goat anti-rabbit IgG polyclonal antibody (Nichirei Bioscience, Tokyo, Japan) for $30 \mathrm{~min}$ at room temperature. Signals were developed as a brown reaction product using peroxidase substrate 3,3'-diaminobenzidine (Nichirei Bioscience). The sections were counterstained with hematoxylin and examined with a BZ-8000 confocal microscope (Keyence, Osaka, Japan).

Statistical analysis. Data are presented as the mean value \pm standard error. The results of the two groups were analyzed using the Mann-Whitney U test. The level of statistical significance was set at $\mathrm{p}<0.05$.

\section{Results}

Improving hypoxic conditions decreases the expression levels of HIF-1 $\alpha$ and EMT factors in HSC-3 cells in vitro. We first examined the in vitro effects of changing oxygen levels on HSC-3 cells by culturing the cells in two different oxygen

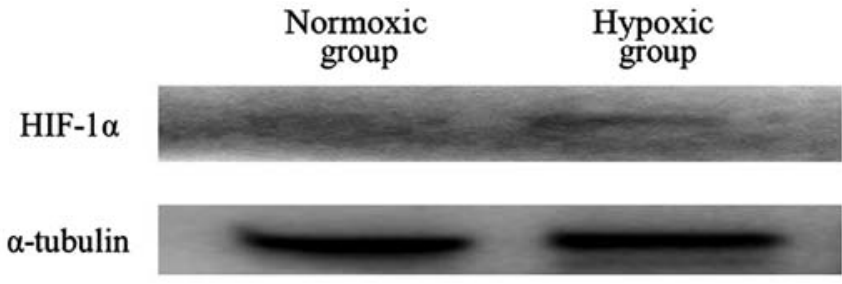

Figure 3. Immunoblot analysis of the expression of HIF-1 $\alpha$ in HSC-3 cells cultured in two different oxygen conditions in vitro.

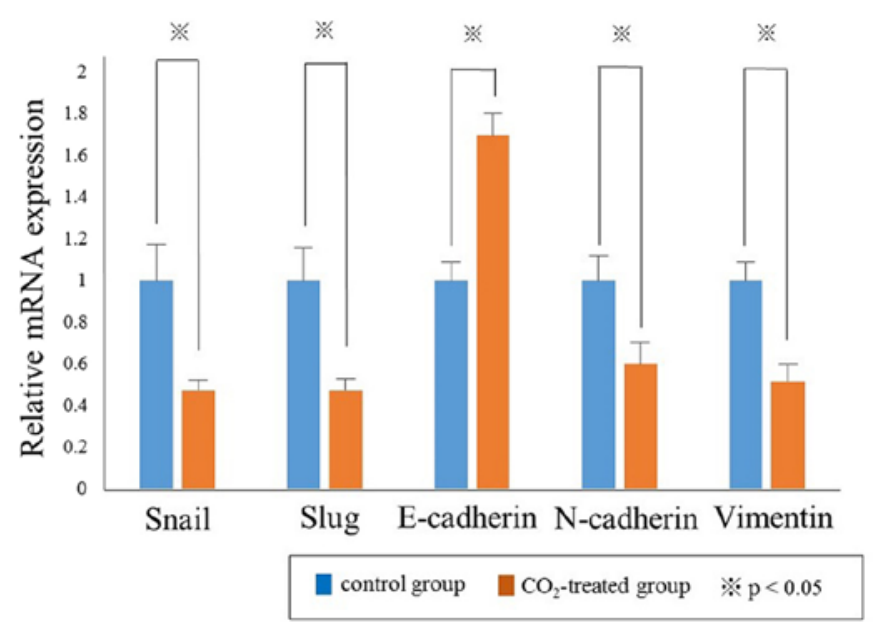

Figure 4. The mRNA expression of Snail, Slug, E-cadherin, $N$-cadherin and Vimentin were evaluated using quantitative real-time PCR $(* \mathrm{p}<0.05)$ in vivo.

conditions. Quantitative real-time PCR analyses revealed that the relative mRNA expression levels of Snail, Slug, $N$-cadherin and Vimentin were significantly increased in hypoxic group compared with those in normoxic group, whereas the expression of E-cadherin was significantly decreased in hypoxic group compared with normoxic group ( $<<0.05$, Fig. 2). Immunoblot analysis showed that increased protein expression of HIF-1 $\alpha$ was observed in hypoxic group, but not in normoxic group (Fig. 3).

Transcutaneous $\mathrm{CO}_{2}$ suppresses the expression levels of HIF-1 $\alpha$ and EMT factors in HSC-3 cells in vivo. We examined the in vivo effects of transcutaneous $\mathrm{CO}_{2}$ on the expression levels of HIF-1 $\alpha$ and EMT factors in HSC-3 cells. Quantitative real-time PCR analyses revealed that the relative mRNA expression levels of Snail, Slug, $N$-cadherin and Vimentin were significantly decreased in the $\mathrm{CO}_{2}$-treated group compared with the control group, in contrast the expression of $E$-cadherin was significantly increased in the $\mathrm{CO}_{2}$-treated group compared with the control group $(\mathrm{p}<0.05$, Fig. 4). Consistent with the results from quantitative realtime PCR, immunohistochemical analysis revealed that decreased expression levels in Snail, Slug, N-cadherin and Vimentin expression with an increased E-cadherin expression was observed in the $\mathrm{CO}_{2}$-treated tumors compared with the control group (Fig. 5). In addition, a western blot analysis showed that increased protein expression of HIF-1 $\alpha$, Snail, Slug, N-cadherin and Vimentin were observed in the control group, but not in the $\mathrm{CO}_{2}$-treated group. In contrast, 


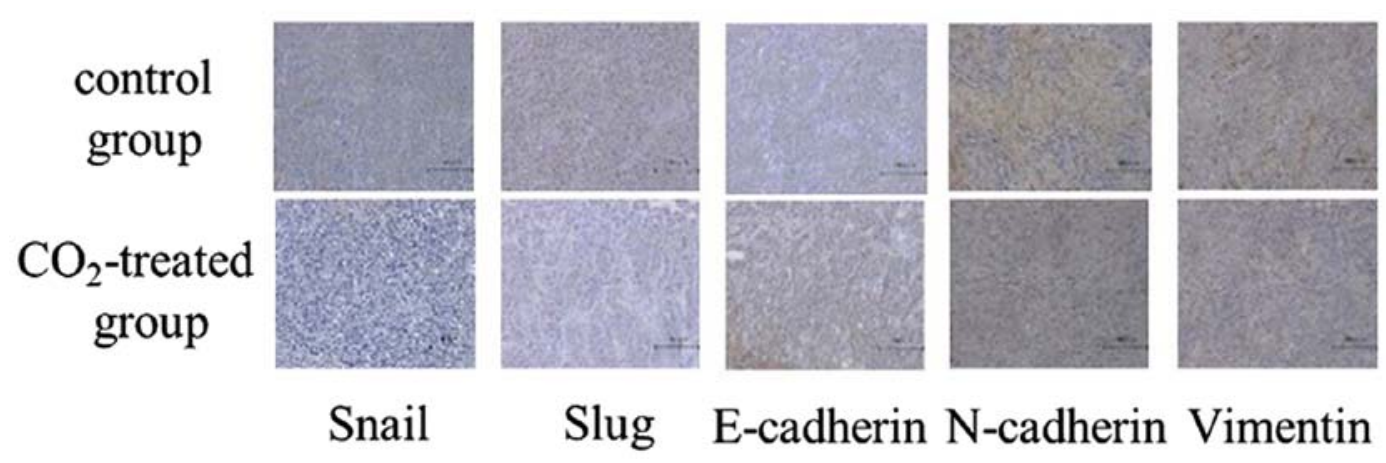

Figure 5. Immunohistochemical staining for EMT factors, Snail, Slug, E-cadherin, N-cadherin and Vimentin in implanted tumors after treatment in vivo.

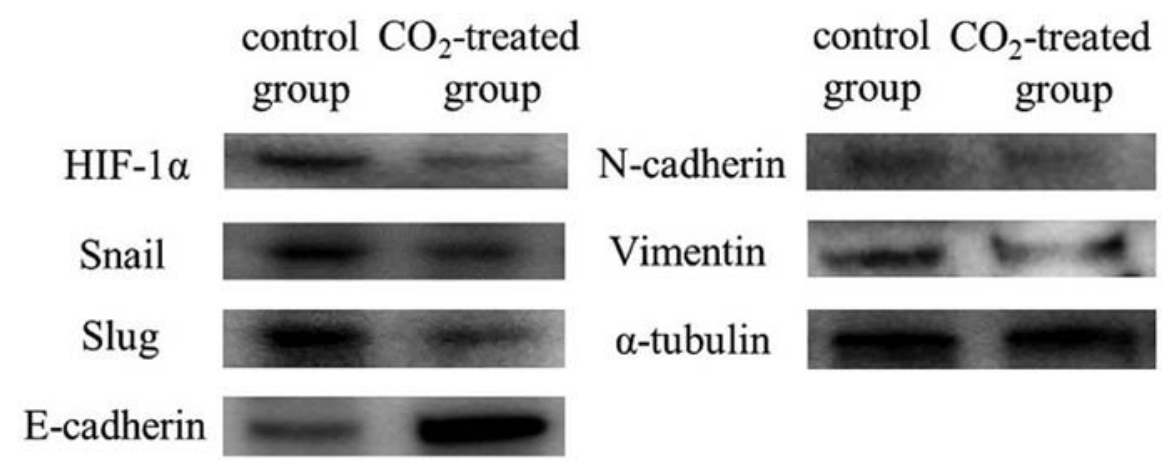

Figure 6. Immunoblot analysis of the expression levels of HIF-1 $\alpha$, Snail, Slug, E-cadherin, N-cadherin and Vimentin in implanted tumors from both treatment groups in vivo.

increased protein expression of E-cadherin was observed in the $\mathrm{CO}_{2}$-treated group (Fig. 6).

\section{Discussion}

OSCC is the most common malignancy in the oral cavity, and is associated with more non-desirable outcomes than any other oral disease because of the highly invasive nature of the tumors and of the cervical lymph node metastasis (30).

Recent studies have demonstrated that the malignant transformation of various carcinomas, including OSCC, is associated with the loss of epithelial differentiation and the gain of the mesenchymal phenotype, a process known as EMT (31,32).

EMT is a physiological phenomenon that involves a loss of polarity and cell-cell adhesion, and that epithelial cells gain characteristics of the mesenchymal cells, which include enhanced motility and matrix resolution (32). EMT itself is an essential cellular function which is involved in tissue construction during normal developmental stages $(33,34)$. Generally, cells undergoing EMT show decreased expression of epithelial markers such as E-cadherin, and increased expression of mesenchymal biomarkers, such as Snail, Slug, $\mathrm{N}$-cadherin and Vimentin (35-38). E-cadherin is one of the major adhesion molecules of epithelial cells. The decreased expression of E-cadherin is an indication of invasion and metastasis, because it liberates carcinoma cells from the primary site and enhances invasion and metastasis (39-41). Thus during the EMT process, E-cadherin is the most important factor, and its expression is a symbol of the occur- rence of EMT. Snail is a zinc finger protein and the first member of a superfamily identified in Drosophila (42-44). Snail 2, known as Slug, has been shown to function in a manner similar to that of Snail; however, Slug displays a distinct tissue distribution $(45,46)$. Both Snail and Slug are considered to be the major transcription factors involved in the modulation of EMT in various types of cancer. They modulate EMT by repressing E-cadherin transcription via binding to the E-cadherin promoter (37). $\mathrm{N}$-cadherin is one of the mesenchymal cadherins, and $\mathrm{N}$-cadherin upregulation has been observed in many types of poorly differentiated tumors (47). In EMT process, 'cadherin switching', the loss of E-cadherin expression and the gain of $\mathrm{N}$-cadherin expression, occurs, upon Snail/Slug expression. Vimentin, which is also promoted by Snail and Slug, is a major protein constituent of the intermediate filaments in normal and neoplastic mesenchymal cells (48). Through the degeneration and production of these factors, the conditions required to generate EMT are established.

Many studies have shown the relationship between the expression levels of EMT factors and the survival rates of patients with SCC (including patients with OSCC) (9-19). The decreased expression of E-cadherin was found to be significantly associated with the survival rates of patients with various cancers, including OSCC $(9,10)$, ovarian cancer (11), gastric cancer (12), prostate cancer (13), colon cancer (14), and lung cancer (15). The expression levels of other important EMT factors, Snail (16), Slug (17), N-cadherin (18), and Vimentin (19), are also closely correlated with the prognosis of patients with OSCC. Moreover, the expression levels of 
these EMT factors are said to be closely associated with tumor differentiation, tumor stage, lymph node metastasis and recurrence in patients with OSCC $(9,10,16-19,49-51)$. Hence, there is a possibility that EMT suppression may improve the prognosis of patients with OSCC.

Hypoxia, which is a common condition in solid tumors, can increase the invasiveness and the metastatic ability of tumor cells (52). Under hypoxic conditions, HIF-1 $\alpha$ is activated in tumor cells; the activation promotes tumor growth, whereas the loss of HIF-1 $\alpha$ activity markedly decreases tumor growth, angiogenesis, and cellular energy metabolism (53). Recent studies have shown that HIF-1 $\alpha$ is a crucial microenvironmental factor that induces the expression levels of EMT factors such as Snail and Vimentin (22-26).

Based on these facts, we hypothesized that oxygen conditions may affect the expression levels of HIF-1 $\alpha$ and EMT factors in OSCC. We first examined the in vitro effects of oxygen levels on HSC-3 cells by culturing the cells in two different oxygen conditions. We revealed that HIF-1 $\alpha$ expression was increased in HSC-3 cells under hypoxic conditions, and in addition, the increased expression of mesenchymal biomarkers with the decreased expression of epithelial markers was observed in hypoxic HSC-3 cells. Consistent with this, Zhang et al have reported that HIF-1 $\alpha$ expression was increased under hypoxic conditions in comparison the expression under normoxic conditions in OSCC in vitro (54). These results indicate that hypoxic condition could affect the expression of EMT factors in OSCC cells in vitro.

We previously reported that the transcutaneous $\mathrm{CO}_{2}$ system improves hypoxia in treated tissue, potentially resulting in an 'artificial Bohr effect' (55). Moreover, we have demonstrated that transcutaneous $\mathrm{CO}_{2}$ suppresses human OSCC growth and metastasis to the regional lymph nodes by both improving hypoxia in treated tissue and increasing mitochondrial apoptosis (27). However, the molecular mechanism of decreased metastatic potential by transcutaneous $\mathrm{CO}_{2}$ has not been addressed.

Based on previous studies, we hypothesized that transcutaneous $\mathrm{CO}_{2}$ could decrease the metastatic potential to lymph nodes by EMT suppression via improving hypoxia in treated tissue. We examined the in vivo effects of transcutaneous $\mathrm{CO}_{2}$ on the expression levels of HIF-1 $\alpha$ and EMT factors using human OSCC xenograft models. Our results showed that transcutaneous $\mathrm{CO}_{2}$ increased the expression levels of epithelial markers with decreased expression levels of HIF-1 $\alpha$ and mesenchymal biomarkers, resulting in EMT suppression.

In the present study, we found that hypoxic conditions increased the expression levels of HIF-1 $\alpha$ and EMT factors in OSCC in vitro, and that oxygenation using transcutaneous $\mathrm{CO}_{2}$ suppressed EMT by improving hypoxia in OSCC in vivo. These results suggest that transcutaneous $\mathrm{CO}_{2}$ could suppress EMT by improving hypoxia and that it may reduce the metastatic potential of OSCC. Our present findings strongly indicate that transcutaneous $\mathrm{CO}_{2}$ may be able to improve the prognosis of patients with OSCC through the suppression of EMT. In conclusion, this is the first report to show that transcutaneous $\mathrm{CO}_{2}$ suppresses the expression levels of EMT factors in human OSCC. Our findings indicate that transcutaneous $\mathrm{CO}_{2}$ suppresses EMT by improving hypoxia and that it could reduce the metastatic potential of OSCC.

\section{Acknowledgements}

We would like to thank Minako Nagata, Maya Yasuda and Kyoko Tanaka for their expert technical assistance.

\section{References}

1. Warnakulasuriya S: Global epidemiology of oral and oropharyngeal cancer. Oral Oncol 45: 309-316, 2009.

2. Kume K, Haraguchi M, Hijioka H, Ishida T, Miyawaki A, Nakamura $\mathrm{N}$ and Ozawa $\mathrm{M}$ : The transcription factor Snail enhanced the degradation of E-cadherin and desmoglein 2 in oral squamous cell carcinoma cells. Biochem Biophys Res Commun 430: 889-894, 2013.

3. Sasahira T, Kirita T, Yamamoto K, Ueda N, Kurihara M, Matsushima S, Bhawal UK, Bosserhoff AK and Kuniyasu H: Transport and Golgi organisation protein 1 is a novel tumour progressive factor in oral squamous cell carcinoma. Eur J Cancer 50: 2142-2151, 2014

4. Thiery JP and Sleeman JP: Complex networks orchestrate epithelial-mesenchymal transitions. Nat Rev Mol Cell Biol 7: 131-142, 2006.

5. Savagner P: Leaving the neighborhood: Molecular mechanisms involved during epithelial-mesenchymal transition. BioEssays 23: 912-923, 2001.

6. Voulgari A and Pintzas A: Epithelial-mesenchymal transition in cancer metastasis: Mechanisms, markers and strategies to overcome drug resistance in the clinic. Biochim Biophys Acta 1796: 75-90, 2009.

7. Grille SJ, Bellacosa A, Upson J, Klein-Szanto AJ, van Roy F, Lee-Kwon W, Donowitz M, Tsichlis PN and Larue L: The protein kinase Akt induces epithelial mesenchymal transition and promotes enhanced motility and invasiveness of squamous cell carcinoma lines. Cancer Res 63: 2172-2178, 2003.

8. Ikenouchi J, Matsuda M, Furuse M and Tsukita S: Regulation of tight junctions during the epithelium-mesenchyme transition: Direct repression of the gene expression of claudins/occludin by Snail. J Cell Sci 116: 1959-1967, 2003.

9. da Silva SD, Morand GB, Alobaid FA, Hier MP, Mlynarek AM, Alaoui-Jamali MA and Kowalski LP: Epithelial-mesenchymal transition (EMT) markers have prognostic impact in multiple primary oral squamous cell carcinoma. Clin Exp Metastasis 32: 55-63, 2015.

10. Fan CC, Wang TY, Cheng YA, Jiang SS, Cheng CW, Lee AY and Kao TY: Expression of E-cadherin, Twist, and p53 and their prognostic value in patients with oral squamous cell carcinoma. J Cancer Res Clin Oncol 139: 1735-1744, 2013.

11. Faleiro-Rodrigues C, Macedo-Pinto I, Pereira D and Lopes CS: Prognostic value of E-cadherin immunoexpression in patients with primary ovarian carcinomas. Ann Oncol 15: 1535-1542, 2004.

12. Zhou YN, Xu CP, Han B, Li M, Qiao L, Fang DC and Yang JM: Expression of E-cadherin and beta-catenin in gastric carcinoma and its correlation with the clinicopathological features and patient survival. World J Gastroenterol 8: 987-993, 2002.

13. Richmond PJ, Karayiannakis AJ, Nagafuchi A, Kaisary AV and Pignatelli M: Aberrant E-cadherin and alpha-catenin expression in prostate cancer: Correlation with patient survival. Cancer Res 57: 3189-3193, 1997.

14. Bondi J, Bukholm G, Nesland JM, Bakka A and Bukholm IR: An increase in the number of adhesion proteins with altered expression is associated with an increased risk of cancer death for colon carcinoma patients. Int J Colorectal Dis 21: 231-237, 2006.

15. Tseng RC, Lee SH, Hsu HS, Chen BH, Tsai WC, Tzao C and Wang YC: SLIT2 attenuation during lung cancer progression deregulates beta-catenin and E-cadherin and associates with poor prognosis. Cancer Res 70: 543-551, 2010.

16. Li YY, Zhou CX and Gao Y: Snail regulates the motility of oral cancer cells via RhoA/Cdc42/p-ERM pathway. Biochem Biophys Res Commun 452: 490-496, 2014.

17. Wushou A, Pan HY, Liu W, Tian Z, Wang LZ, Shali S and Zhang ZY: Correlation of increased twist with lymph node metastasis in patients with oral squamous cell carcinoma. J Oral Maxillofac Surg 70: 1473-1479, 2012. 
18. Zhao D, Tang XF, Yang K, Liu JY and Ma XR: Over-expression of integrin-linked kinase correlates with aberrant expression of Snail, E-cadherin and $\mathrm{N}$-cadherin in oral squamous cell carcinoma: Implications in tumor progression and metastasis. Clin Exp Metastasis 29: 957-969, 2012.

19. Zhou J, Tao D, Xu Q, Gao Z and Tang D: Expression of E-cadherin and vimentin in oral squamous cell carcinoma. Int J Clin Exp Pathol 8: 3150-3154, 2015.

20. Hockel M, Schlenger K, Aral B, Mitze M, Schaffer U and Vaupel P: Association between tumor hypoxia and malignant progression in advanced cancer of the uterine cervix. Cancer Res 56: 4509-4515, 1996.

21. Jing SW, Wang YD, Chen LQ, Sang MX, Zheng MM, Sun GG, Liu Q, Cheng YJ and Yang CR: Hypoxia suppresses E-cadherin and enhances matrix metalloproteinase-2 expression favoring esophageal carcinoma migration and invasion via hypoxia inducible factor-1 alpha activation. Dis Esophagus 26: 75-83, 2013.

22. Krishnamachary B, Zagzag D, Nagasawa H, Rainey K, Okuyama H, Baek JH and Semenza GL: Hypoxia-inducible factor-1-dependent repression of E-cadherin in von HippelLindau tumor suppressor-null renal cell carcinoma mediated by TCF3, ZFHX1A, and ZFHX1B. Cancer Res 66: 2725-2731, 2006.

23. Krishnamachary B, Berg-Dixon S, Kelly B, Agani F, Feldser D, Ferreira G, Iyer N, LaRusch J, Pak B, Taghavi P, et al: Regulation of colon carcinoma cell invasion by hypoxia-inducible factor 1 . Cancer Res 63: 1138-1143, 2003.

24. Lv L, Yuan J, Huang T, Zhang C, Zhu Z, Wang L, Jiang G and Zeng F: Stabilization of Snail by HIF-1 $\alpha$ and TNF- $\alpha$ is required for hypoxia-induced invasion in prostate cancer PC3 cells. Mol Biol Rep 41: 4573-4582, 2014.

25. Wang F, Chang M, Shi Y, Jiang L, Zhao J, Hai L, Sharen G and Du H: Down-regulation of hypoxia-inducible factor-1 suppresses malignant biological behavior of triple-negative breast cancer cells. Int J Clin Exp Med 7: 3933-3940, 2014.

26. Wang N, Dong CR, Jiang R, Tang C, Yang L, Jiang QF, Chen GG and Liu ZM: Overexpression of HIF-1 $\alpha$, metallothionein and SLUG is associated with high TNM stage and lymph node metastasis in papillary thyroid carcinoma. Int J Clin Exp Pathol 7: 322-330, 2013

27. Takeda D, Hasegawa T, Ueha T, Imai Y, Sakakibara A, Minoda M, Kawamoto T, Minamikawa T, Shibuya Y, Akisue T, et al: Transcutaneous carbon dioxide induces mitochondrial apoptosis and suppresses metastasis of oral squamous cell carcinoma in vivo. PLoS One 9: e100530, 2014.

28. Matsui T, Ota T, Ueda Y, Tanino M and Odashima S: Isolation of a highly metastatic cell line to lymph node in human oral squamous cell carcinoma by orthotopic implantation in nude mice. Oral Oncol 34: 253-256, 1998.

29. Okada Y, Akisue T, Hara H, Kishimoto K, Kawamoto T, Imabori M, Kishimoto S, Fukase N, Onishi Y and Kurosaka M The effect of bevacizumab on tumour growth of malignant fibrous histiocytoma in an animal model. Anticancer Res 30: 3391-3395, 2010

30. Jordan RC and Daley T: Oral squamous cell carcinoma: new in sights. J Can Dent Assoc 63: 517-518, 521-525, 1997.

31. Christiansen JJ and Rajasekaran AK: Reassessing epithelial to mesenchymal transition as a prerequisite for carcinoma invasion and metastasis. Cancer Res 66: 8319-8326, 2006.

32. Smith A, Teknos TN and Pan Q: Epithelial to mesenchymal transition in head and neck squamous cell carcinoma. Oral Oncol 49 287-292, 2013.

33. Acloque H, Adams MS, Fishwick K, Bronner-Fraser M and Nieto MA: Epithelial-mesenchymal transitions: The importance of changing cell state in development and disease. J Clin Invest 119: 1438-1449, 2009

34. Thiery JP, Acloque H, Huang RY and Nieto MA: Epithelialmesenchymal transitions in development and disease. Cell 139 871-890, 2009.

35. Huber MA, Kraut $\mathrm{N}$ and Beug $\mathrm{H}$ : Molecular requirements for epithelial-mesenchymal transition during tumor progression. Curr Opin Cell Biol 17: 548-558, 2005.

36. Wheelock MJ, Shintani Y, Maeda M, Fukumoto $Y$ and Johnson KR: Cadherin switching. J Cell Sci 121: 727-735, 2008.
37. Peinado H, Olmeda D and Cano A: Snail, Zeb and bHLH factors in tumour progression: An alliance against the epithelial phenotype? Nat Rev Cancer 7: 415-428, 2007.

38. Peinado H, Portillo F and Cano A: Transcriptional regulation of cadherins during development and carcinogenesis. Int J Dev Biol 48: 365-375, 2004

39. Mattijssen V, Peters HM, Schalkwijk L, Manni JJ, van 't Hof-Grootenboer B, de Mulder PH and Ruiter DJ: E-cadherin expression in head and neck squamous-cell carcinoma is associated with clinical outcome. Int $\mathrm{J}$ Cancer 55: 580-585, 1993

40. Thomas PA, Kirschmann DA, Cerhan JR, Folberg R, Seftor EA, Sellers TA and Hendrix MJ: Association between keratin and vimentin expression, malignant phenotype, and survival in postmenopausal breast cancer patients. Clin Cancer Res 5: 2698-2703, 1999.

41. Yokoyama K, Kamata N, Hayashi E, Hoteiya T, Ueda N, Fujimoto R and Nagayama M: Reverse correlation of E-cadherin and snail expression in oral squamous cell carcinoma cells in vitro. Oral Oncol 37: 65-71, 2001.

42. Tang $\mathrm{CH}$ and Tsai CC: CCL2 increases MMP-9 expression and cell motility in human chondrosarcoma cells via the Ras/Raf/ MEK/ERK/NF- $\kappa \mathrm{B}$ signaling pathway. Biochem Pharmacol 83: 335-344, 2012

43. Barrallo-Gimeno A and Nieto MA: Evolutionary history of the Snail/Scratch superfamily. Trends Genet 25: 248-252, 2009.

44. Nieto MA: The snail superfamily of zinc-finger transcription factors. Nat Rev Mol Cell Biol 3: 155-166, 2002.

45. Parent AE, Newkirk KM and Kusewitt DF: Slug (Snai2) expression during skin and hair follicle development. J Invest Dermatol 130: 1737-1739, 2010.

46. Murray SA, Oram KF and Gridley T: Multiple functions of Snail family genes during palate development in mice. Development 134: 1789-1797, 2007.

47. Li G, Satyamoorthy K and Herlyn M: N-cadherin-mediated intercellular interactions promote survival and migration of melanoma cells. Cancer Res 61: 3819-3825, 2001.

48. Vuoriluoto K, Haugen H, Kiviluoto S, Mpindi JP, Nevo J, Gjerdrum C, Tiron C, Lorens JB and Ivaska J: Vimentin regulates EMT induction by Slug and oncogenic $\mathrm{H}$-Ras and migration by governing Axl expression in breast cancer. Oncogene 30: $1436-1448,2011$

49. Hashimoto T, Soeno Y, Maeda G, Taya Y, Aoba T, Nasu M, Kawashiri S and Imai K: Progression of oral squamous cell carcinoma accompanied with reduced E-cadherin expression but not cadherin switch. PLoS One 7: e47899, 2012.

50. Mandal M, Myers JN, Lippman SM, Johnson FM, Williams MD, Rayala S, Ohshiro K, Rosenthal DI, Weber RS, Gallick GE, et al: Epithelial to mesenchymal transition in head and neck squamous carcinoma: Association of Src activation with E-cadherin downregulation, vimentin expression, and aggressive tumor features. Cancer 112: 2088-2100, 2008.

51. Zhang S, Zhou X, Wang B, Zhang K, Liu S, Yue K, Zhang L and Wang X: Loss of VHL expression contributes to epithelialmesenchymal transition in oral squamous cell carcinoma. Oral Oncol 50: 809-817, 2014.

52. Teppo S, Sundquist E, Vered M, Holappa H, Parkkisenniemi J, Rinaldi T, Lehenkari P, Grenman R, Dayan D, Risteli J, et al: The hypoxic tumor microenvironment regulates invasion of aggressive oral carcinoma cells. Exp Cell Res 319: 376-389, 2013.

53. Wu XY, Fu ZX and Wang XH: Effect of hypoxia-inducible factor 1- $\alpha$ on Survivin in colorectal cancer. Mol Med Rep 3: 409-415, 2010.

54. Zhang Q, Zhang ZF, Rao JY, Sato JD, Brown J, Messadi DV and Le AD: Treatment with siRNA and antisense oligonucleotides targeted to HIF-1alpha induced apoptosis in human tongue squamous cell carcinomas. Int J Cancer 111: 849-857, 2004.

55. Sakai Y, Miwa M, Oe K, Ueha T, Koh A, Niikura T, Iwakura T, Lee SY, Tanaka M and Kurosaka M: A novel system for transcutaneous application of carbon dioxide causing an 'artificial Bohr effect' in the human body. PLoS One 6: e24137, 2011. 